\title{
Influence of moisture content on estimating Young's modulus of full-scale timber using stress wave velocity
}

\author{
Mariko Yamasaki $^{1} \cdot$ Chika Tsuzuki $^{2} \cdot$ Yasutoshi Sasaki $^{1} \cdot$ Yuji Onishi $^{3}$
}

Received: 18 November 2016 / Accepted: 21 February 2017 / Published online: 31 March 2017

(C) The Japan Wood Research Society 2017

\begin{abstract}
The effect of moisture content on the stress wave propagation velocity was investigated in order to estimate the Young's modulus of full-scale timbers in an air-drying state using the measurement of stress wave propagation velocity above the fiber saturation point. Using Japanese cedar lumber, the velocity and the density under high-moisture condition and air-drying states were measured respectively; after measuring the modulus of elasticity in an air-drying state, the moisture content of each condition was measured. By performing numerical analysis on these data, the relationship between the moisture content and the rate of change of velocity of full-scale timbers was derived. This relationship was used to estimate the Young's modulus of the timber in the air-drying state from the velocity in high-moisture condition. First, the velocity and the Young's modulus in an air-drying state were estimated accurately from its density, moisture content and velocity under high-moisture condition. In cases where the density could not be measured, using the database of mechanical properties with the Monte Carlo simulation method, the Young's modulus of the full-scale timber in an air-drying state might be estimated within $20 \%$ accuracy from its moisture content and velocity under high-moisture condition.
\end{abstract}

Mariko Yamasaki

marikoy@agr.nagoya-u.ac.jp

1 Department of Biosphere Resources Science, Graduate School of Bioagricultural Sciences, Nagoya University, 464-8601 Nagoya, Japan

2 Kanefusa Corporation, Oguchi, Aichi 480-0192, Japan

3 Miyagi Prefectural Forestry Technology Institute, Ohira 981-3602, Japan
Keywords Stress wave propagation velocity · Young's modulus $\cdot$ Moisture content

\section{Introduction}

For the purposes of forestry management and carbon stocks meant restraining carbon emissions, wood utilization, especially the material use of the wood which is not broken down of wood as much as possible attracts attention all over the world. In the case of material use, the quality assessment of the actual timber being used may be necessary since timber is a biologically varying material. Among the quality assessments of timber, especially while seeking the mechanical properties of such structural lumber in use, grading according to Young's modulus plays a very important role [1]. Grading timber according to Young's modulus not only allows us to understand the elastic properties of the timber individually, but also allows the fracture strength of the timber to be predicted. In recent years, grading lumber has become a major issue, particularly in Europe and the United States.

Furthermore, if it is possible to make good use of measuring the Young's modulus at the stage of standing trees and $\log$ s to determine its usage application, it is possible to utilize the timber more efficiently, subsequently adding value to the timber. Currently, in Japan, the usage of logs is mainly determined based on visual observations of the shape. However, studies on selecting a timber according to future application using the Young's modulus of standing tree and logs have been performed (for example, 2-10]). In these studies, the longitudinal vibration test or ultrasonic and stress waves for the Young's modulus measurement were adopted and the qualitative effectiveness has been shown. However, of course, the Young's modulus of log, 
namely green wood under highly moist condition is different from the value of the Young's modulus in the air-drying state when being used. Therefore, it is necessary to have some sort of moisture correction to estimate the Young's modulus in the air-drying state. In the cases of stress wave and ultrasound, since the free water within the cell pores cannot follow the vibration, it is known that the Young's modulus, calculated from the velocity and density, is overestimated above the fiber saturation point (FSP) [11-14].

Moisture correction on the velocity or density is, therefore, also required to determine the Young's modulus under high-moisture condition. For Young's modulus measurement during high-moisture condition via the stress wave method, Sobue [11] proposed the mobility of free water and performed the moisture correction by adjusting the density, and some researchers used this approach in their reports $[12,14]$. In the researches which investigate the influence of moisture content of wood on the velocity, they measure the velocity some times in the course of the drying process generally. Therefore, the size of a test specimen is around $500 \mathrm{~mm}$ in length and it is smaller than full-scale timber in most cases for experimental reasons. However, in the case of wood, there are large differences between small specimen and full-scale timber used in the actual building because full-scale timber has some defect like knots and intra-subject variation. Therefore, it is important to use the full-scale timber as specimen for the investigation of mechanical or physical properties of wood used in the buildings. Unterwieser and Schickhofer [10] were used the relatively large spruce specimen and investigated the influence of moisture content on the velocity and dynamic Young's modulus. They measured the velocity by two methods, that is, measurements of natural frequency and ultrasonic runtime, then reported the empirical formula to obtain the velocity at $12 \%$ moisture content from that below and above FSP.

In this study, with the aim of estimating the Young's modulus of a full-scale timber in the air-drying state from the stress wave propagation velocity, measured in highmoisture condition, the effect of moisture content on the stress wave propagation velocity was examined. Specimen was general size of structural timber in Japan, which had larger dimension than that used in the Unterwieser and Schickhofer's research [10]. Because the full-scale timber was used as a test specimen, it was difficult to dry the specimen so as to uniformly distribute moisture. Therefore, in this study the experiment was done only twice at the green condition and the air-drying state and the numerical method was used for analysis. Specifically, using Japanese cedar lumber, the density and the stress wave propagation velocity in high-moisture condition and in the air-drying state were measured, respectively; after bending test to measure the modulus of elasticity in the air-drying state, the moisture content was measured using the oven-drying method. By carrying out numerical analysis on these data, the relationship between the moisture content and the rate of change of velocity in the timber was derived. Using this relationship, the method of estimating the Young's modulus of the full-scale timber in the air-drying state from the stress wave propagation velocity in high-moisture condition was suggested and its effectiveness was verified.

\section{Materials and methods}

\section{Determination of moisture content: stress wave velocity curve}

\section{Full-scale test for analysis}

First, the symbols in the present paper are listed in Table 1. To examine the relationship between the stress wave propagation velocity and moisture content of the full-scale timber as well as the relationship between Young's modulus with these former two parameters, the following experiments were conducted. The test specimens were full-scale sawn lumbers of Japanese cedar (Cryptomeria japonica D. Don) from the Miyagi Prefecture in Japan. The dimensions of the specimens were $120(b) \times 210(h) \times 4000(l) \mathrm{mm}$. The number of test specimens, $n$, was 38 . Before drying [moisture content, $u_{\mathrm{b}}=(113.2 \pm 29.5) \%$ ] and after drying [moisture content, $u_{\mathrm{a}}=(16.4 \pm 8.3) \%$ ], the density $(\rho$, calculated from the weight and volume), and the stress wave propagation velocity (before drying, $V_{\mathrm{b}}$; after drying, $V_{\mathrm{a}}$ ) of each specimen were measured. For the numerical analysis, to be described later, group A with a moisture content higher than the fiber saturation point (hereafter, FSP) after drying $\left(u_{\mathrm{a}}>28 \%\right.$; number of test specimens, $\left.n=6\right)$ and group B with a moisture content lower than the FSP after drying $\left(u_{\mathrm{a}}<28 \%\right.$; number of test specimens, $\left.n=32\right)$ were created by adjusting the drying period. As for drying condition, one-half specimens were dried under high temperature (outsourcing, drying period of 7 days, maximum dry-bulb temperature of $120^{\circ} \mathrm{C}$ ) and the others were dried under middle temperature (at Miyagi Prefectural Forestry Technology Institute, drying period of 14 days, initial drybulb temperature of $60^{\circ} \mathrm{C}$ and final dry-bulb temperature of $\left.75^{\circ} \mathrm{C}\right)$.

The stress wave propagation velocity was measured using a portable stress wave propagation timer, FAKOPP, with installation of transmission sensors at the two ends of the specimen (cross sections of timber), respectively. As shown in Fig. 1, the sensor installation positions on the plane of timber ends were at three points, dividing four equal portions along the direction of beam height. By taking three measurements at each point, the average 
Table 1 Symbols in the present paper

\begin{tabular}{lll}
\hline Mechanical properties & $V$ & Stress wave velocity $\left(\mathrm{m} \mathrm{s}^{-1}\right)$ \\
& $u$ & Moisture content $(\%)$ \\
& $V_{u} / V_{0}$ & The ratio of stress wave velocity at certain moisture content $\left(V_{u}\right)$ to stress wave velocity at $0 \%$ moisture content \\
& & $\left(V_{0}\right)$ (Change rate of stress wave velocity) \\
& $V_{28 \mathrm{H}}$ & Stress wave velocity at $u=28 \%$ calculated by $u-V_{u} / V_{0}$ curve above FSP $(u \geqq 28 \%)\left(\mathrm{m} \mathrm{s}^{-1}\right)$ \\
& $V_{28 \mathrm{~L}}$ & Stress wave velocity at $u=28 \%$ calculated by $u-V_{u} / V_{0}$ curve below FSP $(u \leqq 28 \%)\left(\mathrm{m} \mathrm{s}^{-1}\right)$ \\
& $\rho$ & Density $\left(\mathrm{kg} \mathrm{m}^{-3}\right)$
\end{tabular}

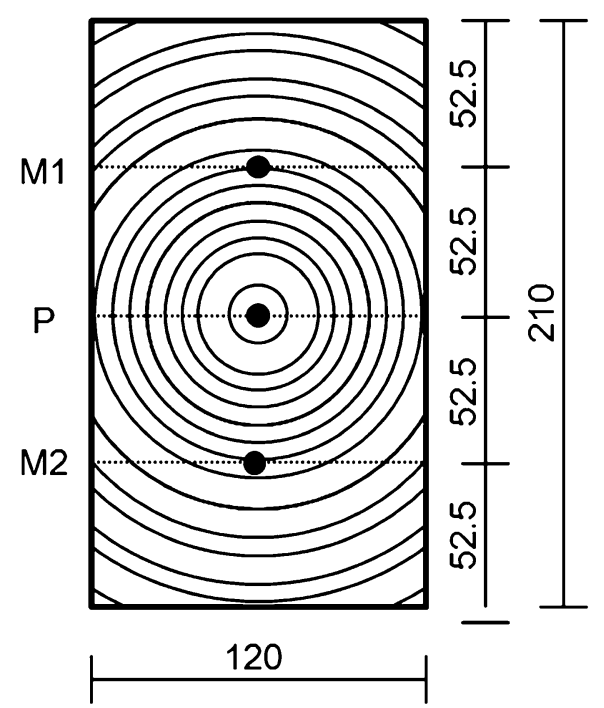

Unit: mm

Fig. 1 Measurement points of stress wave velocity in end section

value of stress wave propagation velocity at that point was obtained. From the stress wave propagation velocities at the three points per test specimen (M1, P, M2), P data are the pith data, whereas the average values of M1 and $\mathrm{M} 2$ are the data for mature wood because they were located outside from 15 annual rings. Besides, averaging the values using $(\mathrm{P} 1+(\mathrm{M} 1+\mathrm{M} 2) / 2) / 2)$ gave the average data of the test specimen. In addition, in the study by Guan et al. [14], the relationship between the moisture content and the rate of change of velocity using small test specimens, taken from the heartwood or sapwood was examined. In this study, the measurement points M1 and M2 were different, which may or may not be sapwood. Clear division between heartwood and sapwood for these data was impossible.

Furthermore, to examine the modulus of elasticity (MOE) in the air-drying state, a full-scale bending test on specimens after drying was carried out. The bending test, based on a standard test method that is ISO-compliant, was a four-point bending test with a distance of $3780 \mathrm{~mm}$ between the supporting points (18 times of the beam height) and trisecting the distance between the supporting and load point into $1260 \mathrm{~mm}$ (6 times of the beam height). With the stroke control of constant displacement speed set at $20 \mathrm{~mm} \mathrm{~min}{ }^{-1}$, the loading was performed using full-scale mechanical testing equipment. The bending load from the load cell, attached to the equipment, as well as the bending deflection from the displacement gauge, installed on the neutral axis of the specimen center, was measured using data loggers, respectively. These captured data were recorded in a personal computer. From the relationship of the measured load and the central bending deflection, the modulus of elasticity (MOE) was determined.

After completing the bending test, samples with width of about $20 \mathrm{~mm}$ were taken in longitudinal direction of timber, approximately $1 \mathrm{~m}$ from the end of the remaining fractured specimens to determine the moisture contents after drying, $u_{\mathrm{a}}$, using the oven-drying method. Then the moisture contents after drying, $u_{\mathrm{b}}$, was obtained by weight change. 


\section{Numerical analysis}

Using some data of full-scale timbers in the "Full-scale test for analysis" as described above, the transition of stress wave propagation velocity, $V$, with the change in moisture content of the full-scale timber [hereafter, named the relationship of moisture content $(u)$ - rate of change of velocity $\left.\left(V_{u} / V_{0}\right)\right]$ was determined using the numerical analysis method, shown below. A schematic diagram for the relationship of $u-V_{u} / V_{0}$ is shown in Fig. 2. With the horizontal axis as the moisture content $(u)$, the vertical axis as the rate of change of velocity $\left(V_{u} / V_{0}\right)$ is normalized when the moisture content is $0 \%$. According to Sandoz [3], it is considered that the influence of moisture content on stress wave propagation velocity of the timber is different below the FSP, containing only bound water, from above the FSP, containing also free water. Therefore, in this study, it was assumed that the $u-V_{u} / V_{0}$ relationship shows bilinear behavior before and after the FSP (for example, [3]). The

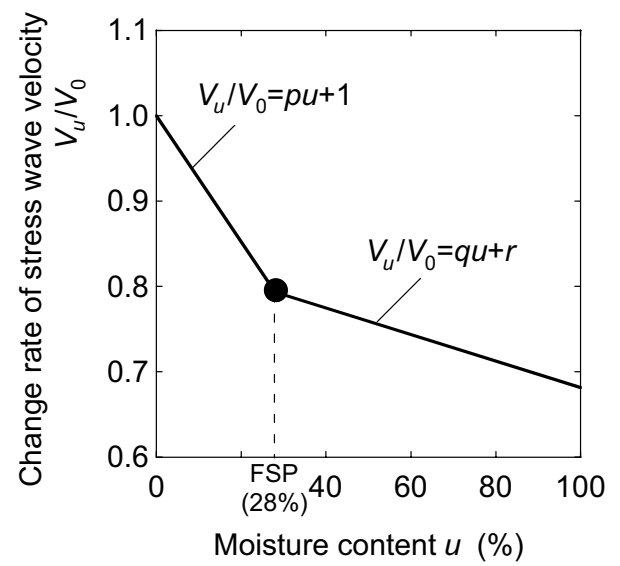

Fig. 2 Schematic diagram of moisture content-the change rate of stress wave velocity curve relationship is represented by the Eq. (1), below the FSP, and Eq. (2), above the FSP.

$\frac{V_{u}}{V_{0}}=p u+1 \quad(u \leqq 28 \%)$,

$\frac{V_{u}}{V_{0}}=q u+r \quad(u \geqq 28 \%)$.

To obtain the bilinear equation, $V_{0}$ is required to serve as the reference. Since $V_{0}$ is the stress wave propagation velocity in absolute-dry condition, its measurement using a full-scale timber is very difficult. Thus, in the present numerical analysis, a valid $V_{0}$ was first estimated from the range of 4000-6000 $\mathrm{m} \mathrm{s}^{-1}$ with respect to the experimental results of both before drying and after drying via the following method. Using this estimated value to determine the coefficients of Eqs. (1) and (2), the validities of both equations were verified. The analysis procedure is as follows:

1. Prepare the following set of data to be used in the analysis; Group A: A $i\left(u_{\mathrm{b}} i, V_{\mathrm{b}} i, u_{\mathrm{a}} i, V_{\mathrm{a}} i\right),(i=1,2, \ldots, 6),\left(u_{\mathrm{a}} i\right.$ $>28 \%)$, Group B: Bj $\left(u_{\mathrm{b}} j, V_{\mathrm{b}} j, u_{\mathrm{a}} j, V_{\mathrm{a}} j\right),(j=1,2, \ldots, 31)$, $\left(u_{\mathrm{a}} j<28 \%\right)$. As described below, for verification of the analysis, one set of experimental values in Group B was not used in the numerical analysis.

2. With respect to one data set, $\mathrm{A} i(i=1,2, \ldots, 6)$, in Group A, conduct the analysis following steps (3)-(7);

3. Assuming $V_{0}$ as a reference for the rate of change of velocity within the range $4000-6000 \mathrm{~m} \mathrm{~s}^{-1}$ at intervals of $10 \mathrm{~m} \mathrm{~s}^{-1}$ in this study, conduct calculations following steps (4) and (5) for the one assumed value;

4. Using the data set of $\mathrm{A} i$ and the assumed $V_{0}$ in step (3), calculate the coefficients of $p\left(V_{0}\right), q\left(V_{0}\right), r\left(V_{0}\right)$ for the bilinear relationship of $V_{u} / V_{0}$ from Eqs. (1) and (2) (Fig. 3a). These coefficients vary with respect to the assumed value of $V_{0}$ (Fig. 3b).

5. If the assumed value of $V_{0}$ in step (4) is close to the true value when the coefficients of $p\left(V_{0}\right), q\left(V_{0}\right), r\left(V_{0}\right)$
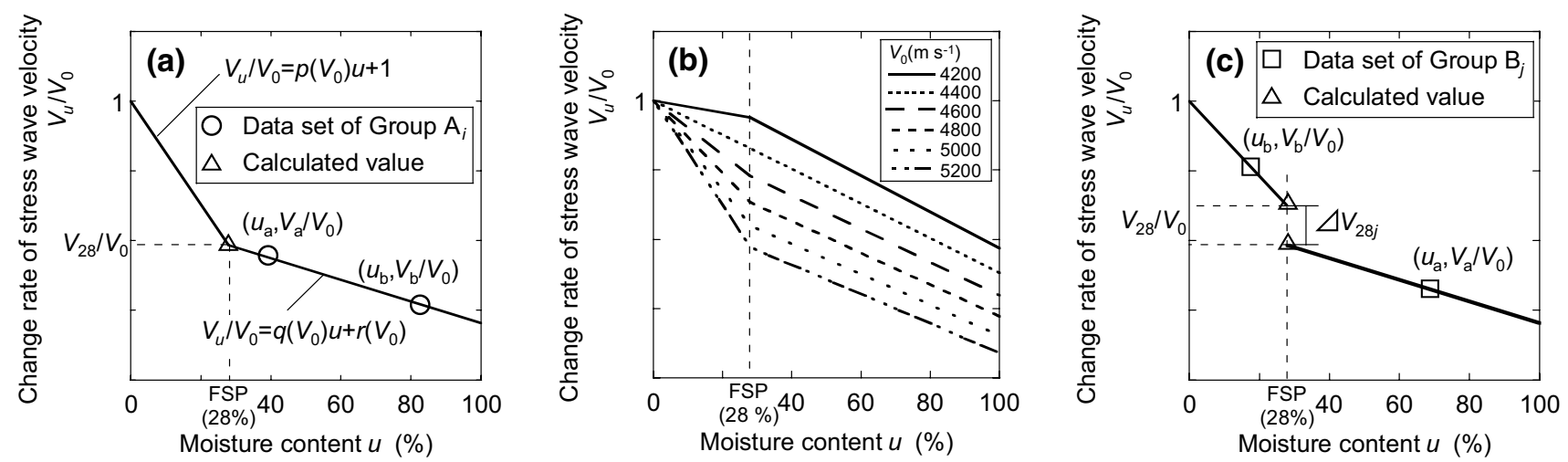

Fig. 3 Schematic diagrams of numerical analysis. FSP means fiber saturation point (at $28 \%$ moisture content in this paper) 
are valid values, use another set of experimental data to calculate the velocity at the FSP, $V_{28 \mathrm{~L}}$, from the side of low moisture content $(u \leqq 28 \%)$ and the velocity at the FSP, $V_{28 \mathrm{H}}$, calculated from the side of high moisture content $(u \geqq 28 \%)$, both results should match.

Thus, to obtain reasonable coefficients of $p, q$, and $r$, the following method of verifying data was created using the data set of Group B, B $j(j=1,2, \ldots, 31)$.

The calculated velocity at the FSP from the side of low moisture content, $V_{28 \mathrm{~L}}$, is obtained by transforming Eq. (1) into Eq. (3); the calculated velocity at the FSP from the side of high moisture content, $V_{28 \mathrm{H}}$, is obtained by transforming Eq. (2) into Eq. (4).

$V_{28 \mathrm{~L}}=\frac{V_{\mathrm{a}} \cdot(28 p+1)}{u_{\mathrm{a}} \cdot p+1}$,

$V_{28 \mathrm{H}}=\frac{V_{\mathrm{b}} \cdot(28 q+r)}{u_{\mathrm{b}} \cdot q+r}$.

After substituting the coefficients of $p\left(V_{0}\right), q\left(V_{0}\right), r\left(V_{0}\right)$ from the relationship of $u-V_{u} / V_{0}$ obtained in Step (4) and one of data set in Group $\mathrm{B}, \mathrm{B} j$, into these equations, then the difference in both, $\Delta V_{28}$ i, is calculated using Eq. (5) (Fig. 3c).

$\Delta V_{28} j=\left|V_{28 \mathrm{~L}} j-V_{28 \mathrm{H}} j\right|$.

Calculate the sum of $\Delta V_{28} j, \mathrm{SA}\left(V_{0}\right)$, corresponding to the 31 sets of $\mathrm{Bj}$;

$\mathrm{SA}\left(V_{0}\right)=\sum_{j=1}^{31} \Delta V_{28} j$

6. Corresponding to A $i$, set the $V_{0} i$ to be $V_{0}$ to minimize the obtained $\mathrm{SA}\left(V_{0}\right)$ in Step (5);

7. Corresponding to the $V_{0} i$ obtained in Step (6), set each coefficient of $p\left(V_{0} i\right), q\left(V_{0} i\right)$ and $r\left(V_{0} i\right)$ to be $p i, q i$ and $r i$, as the analysis results of $\mathrm{A} i$;

8. Compute the coefficients $p, q, r$ of Eqs. (1) and (2) by averaging the values from the analysis results of all Group A.

\section{Full-scale test for the verification of analysis result}

To validate the $u-V_{u} / V_{0}$ relationship obtained in the above analysis, verification was carried out as follows. Using the experimental groups described in "Full-scale test for analysis", the one remaining data set not used was subjected to the verification method. The relationship of data for analysis and data for verification is shown in Fig. 4.

Specifically, the above numerical analysis was carried out using 31 sets of data, excluding one set of experimental

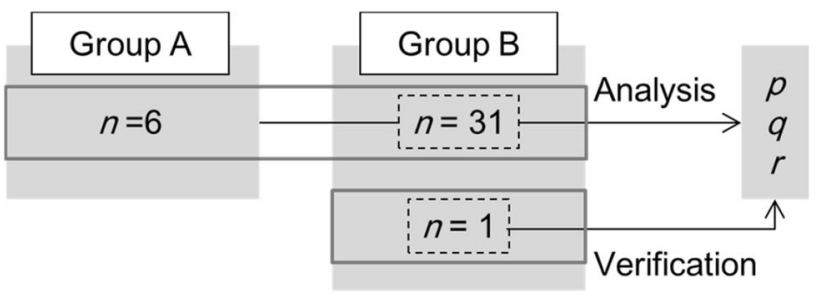

$n$ : Number of specimen

Fig. 4 Schematic diagrams of data using numerical analysis and verification

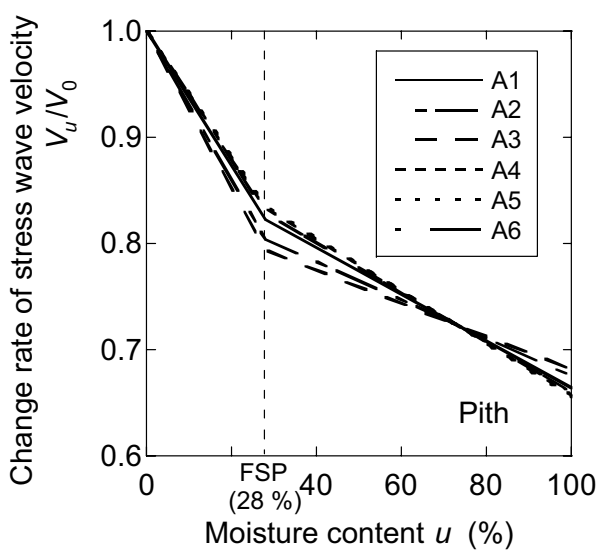

Fig. 5 Moisture content-the change rate of stress wave velocity curve of Group A's specimens obtained by numerical analysis

values, from Group B $(n=32)$ to determine the $u-V_{u} / V_{0}$ relationship according to the preceding paragraph. The validity of the $u-V_{u} / V_{0}$ relationship, obtained in the analysis, was verified using the one set of data that was not used for the analysis at that time. From a combination of specimens for analysis and the specimen for verification, the analysis result for each specimen of Group A $(n=6)$ can be obtained 31 ways. In other words, using the other 31 specimens in Group B for the analysis of each specimen in Group A, the analysis results on the number of specimens in Group A ( $n=6$; coefficients of relationship, $p, q$, $r$ ) are obtained for the exclusive one specimen in Group B, as shown in Fig. 5. These average values can be verified by the exclusive specimen in Group B.

\section{Results and discussion}

\section{Relationship between moisture content and the rate of change of stress wave velocity}

The physical properties and Young's modulus of the cedar full-scale specimens are listed in Table 2. Looking at the influence of the measurement points along end 


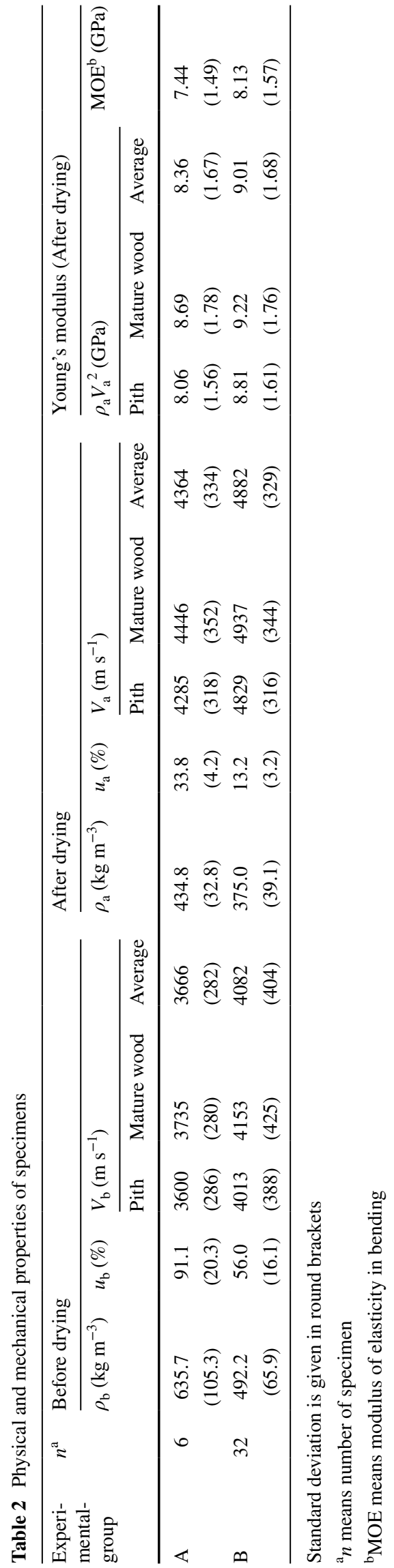

section on the stress wave propagation velocity, the measurements on the mature wood are slightly larger than the measurement on the pith for both before and after drying of both Groups A and B. This trend can also be seen in previous research [15]. However, there was also no significant statistical difference between both groups. For the Young's modulus after drying, comparing the $\rho_{\mathrm{a}(\mathrm{o})} V_{\mathrm{a}(\mathrm{o})}{ }^{2}$, calculated from density and stress wave propagation velocity and the $\mathrm{MOE}_{\mathrm{a}(\mathrm{o})}, \rho V^{2}$ was larger than MOE by $8.3 \%$ at the measurement points of pith and by $13.9 \%$ at the mature wood, respectively. It is considered that this tendency, which was also observed in the previous study [16], is due to the frequency-dependent (time-dependent) influence of the Young's modulus caused by the viscoelasticity of the timber.

By conducting numerical analysis on these data, the $u-V_{u} / V_{0}$ relationship of full-scale timber was obtained. Based on the respective measurement points of the stress wave propagation velocity for the analysis, the coefficients of the $u-V_{u} / V_{0}$ relationship are summarized in Table 3. As for the moisture content below FSP, the slopes of the relationship, $p$, were at -0.00645 and -0.00586 on the pith and the mature wood, respectively; whereas the slopes for above FSP, $q$, were at -0.00215 and -0.00218 , respectively. There was not much difference between measurement points; but regardless of measurement point, the rate of change of velocity with change in moisture content below the FSP was larger than that above the FSP. Such tendency has also been observed in a lot of previous studies (for example, $[3,10-12,14$, 17-19]). The slopes, $p$, were about three times of the slopes, $q$. First, this could be due to the well-known fact that the Young's modulus increases with a decrease in the moisture content below the FSP, whereas the Young's modulus of the timber is constant above the FSP. Even above the FSP, the velocity does not become constant and changes under the influence of moisture content because the free water in the cell lumen cannot follow the vibration with high speed [3]. The results of the regression analysis on the extracted data of Guan et al. [14] [Japanese cedar, size of specimen: $20(\mathrm{~T}) \times 20(\mathrm{R}) \times 500(\mathrm{~L}) \mathrm{mm}]$ are also shown in Table 3. Comparing the present analysis results with the results of Guan, as shown in Table 3, the overall trends are generally similar. However, looking in detail, the rate of change of velocity with respect to moisture content in the present analysis results is larger than that in the results of Guan. Since the suggested results of Guan here are only intended to fit the regression equation into one data set, the number of samples was very limited. Furthermore, since the size of the specimen and the measurement methods are different, it was not possible to simply compare and was suggested that the full-scale timber is susceptible to moisture content. 
Table 3 Coefficients of the relational expression of moisture content and change rate of velocity

\begin{tabular}{|c|c|c|c|c|c|c|c|c|c|c|}
\hline & \multirow[t]{2}{*}{ Measurement position } & \multirow[t]{2}{*}{$n^{\mathrm{a}}$} & \multirow{2}{*}{\multicolumn{2}{|c|}{$V_{0}\left(\mathrm{~m} \mathrm{~s}^{-1}\right)$}} & \multicolumn{2}{|c|}{$V_{u} / V_{0}=p u+1$} & \multicolumn{4}{|c|}{$V_{u} / V_{0}=q u+r$} \\
\hline & & & & & $p(1 / \%)$ & & $q(1 / \%)$ & & $r$ & \\
\hline \multirow[t]{3}{*}{ Present } & Pith & 6 & 5302 & $(312)$ & -0.00645 & $(0.00061)$ & -0.00215 & $(0.00038)$ & 0.8796 & $(0.0277)$ \\
\hline & Mature wood & 6 & 5390 & $(309)$ & -0.00586 & $(0.00056)$ & -0.00218 & $(0.00035)$ & 0.8970 & $(0.0257)$ \\
\hline & Average & 6 & 5346 & $(309)$ & -0.00616 & $(0.00057)$ & -0.00216 & $(0.00036)$ & 0.8880 & $(0.0262)$ \\
\hline \multirow[t]{3}{*}{ Guan $^{\mathrm{b}}$} & Heartwood & 1 & - & & -0.00541 & & -0.00161 & & 0.8895 & \\
\hline & Sapwood & 1 & - & & -0.00396 & & -0.00108 & & 0.8979 & \\
\hline & Overall & 2 & - & & -0.00498 & & -0.00123 & & 0.8836 & \\
\hline
\end{tabular}

Standard deviation is given in round brackets

${ }^{\mathrm{a}} n$ means number of analyzed data set (Group A)

${ }^{\mathrm{b}}$ Analyzed with data extracted from Guan [14]. Size of Guan's specimen is $20(\mathrm{~T}) \times 20(\mathrm{R}) \times 500(\mathrm{~L}) \mathrm{mm}$

The validity of the $u-V_{u} / V_{0}$ relationship derived in this method was verified using the one dataset, which was not used in the numerical analysis to determine the coefficients for the $u-V_{u} / V_{0}$ relationship, among the experimental data of Group B. In other words, using the relational expressions obtained, the stress wave propagation velocity in the air-drying state (moisture content after drying, $\left.u_{\mathrm{a}}\right), V_{\mathrm{a}(\mathrm{e})}$, was estimated from the stress wave propagation velocity in high-moisture condition (moisture content before drying, $\left.u_{\mathrm{b}}\right), V_{\mathrm{b}(\mathrm{o})}$; then the estimated value $V_{\mathrm{a}(\mathrm{e})}$ and the observed value $V_{\mathrm{a}(\mathrm{o})}$ were compared. The values used are the coefficients of the $u-V_{u} / V_{0}$ relationship, shown in Table 3. The relationship of the estimated value, $V_{\mathrm{a}(\mathrm{e})}$, and the observed value, $V_{\mathrm{a}(\mathrm{o})}$, is plotted in Fig. 6a. The estimation accuracy (estimated value/ observed value) of $V_{\mathrm{a}}$ is listed in Table 4. As shown in these figure and tables, for any measurement point of the pith and mature wood, the estimated values and the observed values also showed very good agreement. Additionally, to examine the versatility of this relationship, it was verified using the experimental data of Sandoz [2] and Unterwieser and Schickhofer [10]. Using spruce as a test specimen [Size of specimen: 100 (Width) $\times 140$ (Height) $\times 2800$ (Length) $\mathrm{mm}$ ], Sandoz examined the correlation between the ultrasonic velocity, measured at $22 \%$ moisture content and the ultrasonic velocity, measured at $14 \%$ moisture content. Therefore, for the results of Sandoz, the velocity at $14 \%$ moisture content was estimated from the velocity at $22 \%$ moisture content using the $u-V_{u} / V_{0}$ relationship, obtained in the present analysis; these estimated values were compared with the observed values. The results are shown in Fig. 6b. The estimation accuracy was $0.99 \pm 0.01$ which was very good. Similarly, for the experimental data reported by Unterwieser and Schickhofer, which were obtained using the relatively large test specimen of spruce [Size of specimen: $202 \mathrm{~mm}$ and $98 \mathrm{~mm}$ (Width) $\times 49 \mathrm{~mm}$ and $41 \mathrm{~mm}$ (Height) $\times 4500$ (Length) $\mathrm{mm}$ ], the velocity at $12 \%$ moisture content was estimated from the ultrasonic velocity above FSP. As a result, the estimation accuracies were $1.02 \pm 0.001$ (using coefficients of the relational expression at pith shown in Table 3), $1.01 \pm 0.001$ (at mature), $1.02 \pm 0.001$ (for average), respectively, which also showed very good accuracy. Hence, it is considered that the $u-V_{u} / V_{0}$
Fig. 6 Relationship between estimated and observed velocity
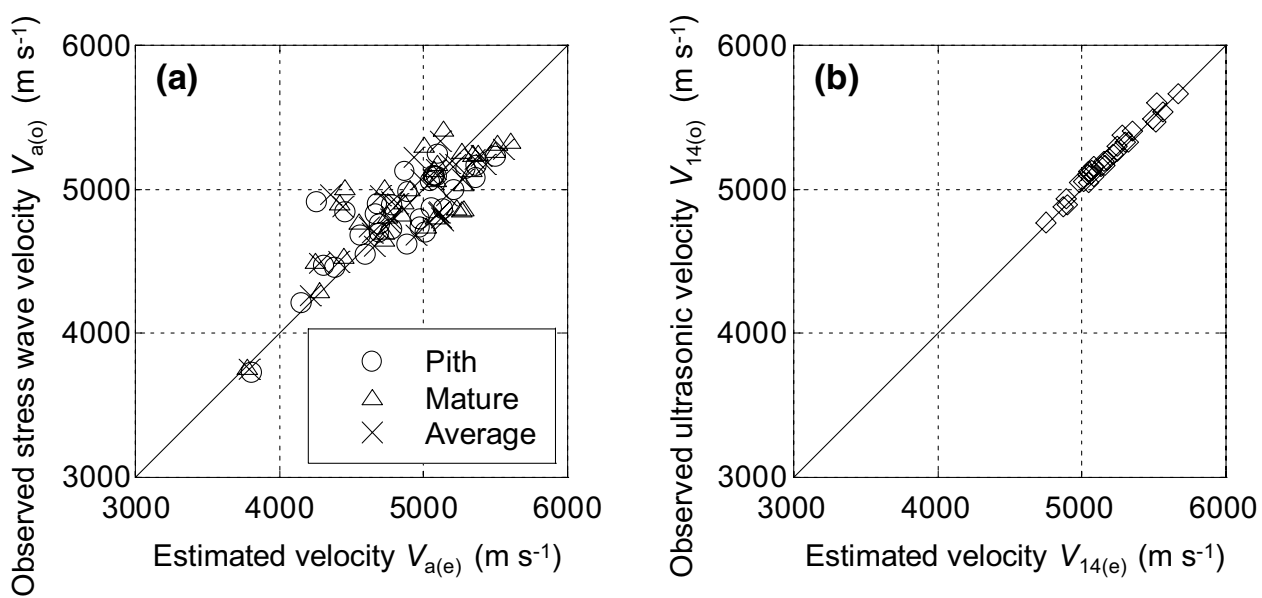


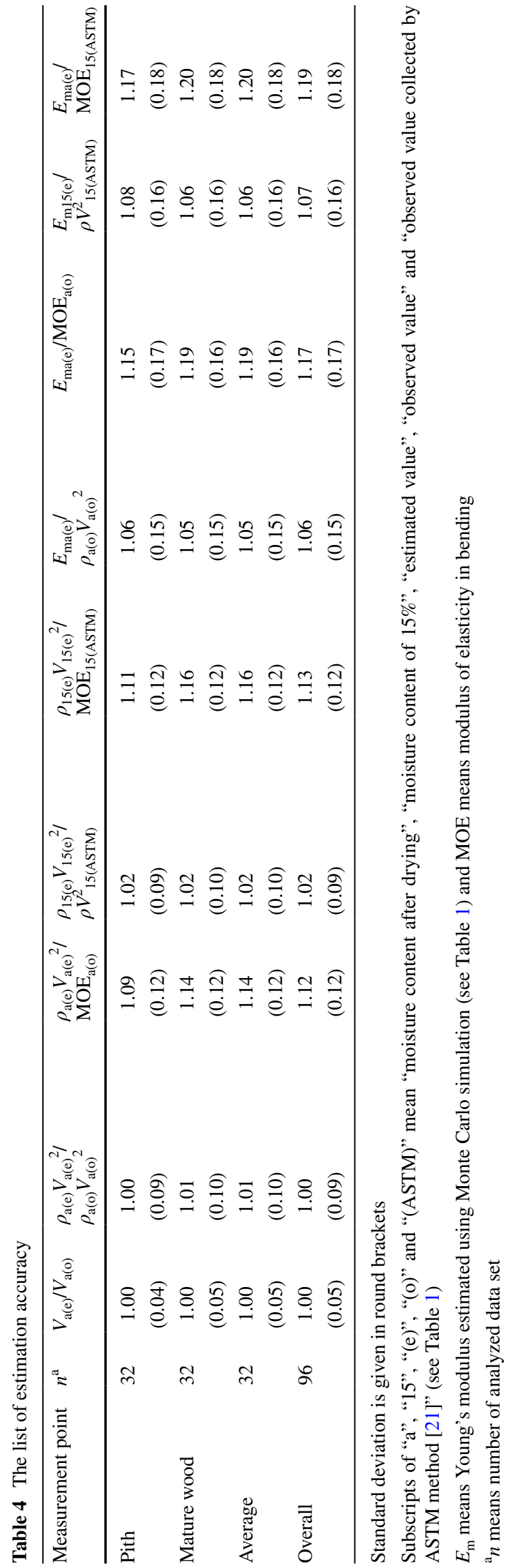

relationships obtained by the analysis of this study are valid and also excellent in versatility.

\section{Estimation of Young's modulus in an air-drying state using stress wave velocity measured under high-moisture content condition}

\section{Comparison with experimental MOE}

Using the estimated stress wave propagation velocity in the air-drying state (low moisture content state), $V_{\mathrm{a}(\mathrm{e})}$, from the previous section, the Young's modulus $\rho_{\mathrm{a}(\mathrm{e})} V_{\mathrm{a}(\mathrm{e})}{ }^{2}$ in the air-drying state (moisture content after drying, $u_{\mathrm{a}}$ ) was calculated. The aim of this study is to estimate the Young's modulus in the air-drying state from the stress wave propagation velocity of the high-moisture condition. Thus, without measuring the $\rho_{\mathrm{a}(\mathrm{o})}$, the required density under the moisture content after drying, $\rho_{\mathrm{a}(\mathrm{e})}$ at $u_{\mathrm{a}}$, in the calculation was derived from the density under high-moisture condition, $\rho_{\mathrm{b}(\mathrm{o})}$ using the following equation with consideration of volume change of timber.

$$
\begin{aligned}
\rho_{\mathrm{a}(\mathrm{e})}= & \frac{\left(1+u_{\mathrm{a}}\right)}{\left(1+u_{\mathrm{b}}\right)} \\
& \cdot \frac{\left(1+\alpha_{\mathrm{L}}\right) \cdot\left(1+\alpha_{\mathrm{R}}\right) \cdot\left(1+\alpha_{\mathrm{T}}\right)}{\left(1+100 u_{\mathrm{a}} \delta_{\mathrm{L}}\right) \cdot\left(1+100 u_{\mathrm{a}} \delta_{\mathrm{R}}\right) \cdot\left(1+100 u_{\mathrm{a}} \delta_{\mathrm{T}}\right)} \rho_{\mathrm{b}(\mathrm{o})} .
\end{aligned}
$$

Here, $\alpha$ is overall shrinkage rate; $\delta$ is the average shrinkage rate for $1 \%$ moisture content; the subscripts $\mathrm{L}, \mathrm{R}$ and $\mathrm{T}$ indicate the longitudinal direction, the radial direction and the tangential direction of timber, respectively. In this paper, though all the moisture contents, $u$, are expressed with the $\%$ notation, the $u_{\mathrm{a}}$ and $u_{\mathrm{b}}$ in Eq. (7), are not expressed with $\%$ notation. Extracted from the literature [20] for this study, $\alpha_{\mathrm{L}}=0.19 \%, \alpha_{\mathrm{R}}=2.68 \%$ and $\alpha_{\mathrm{T}}=$ $6.57 \%$; dividing these values by 28 , the values of $\delta_{\mathrm{L}}, \delta_{\mathrm{R}}$, $\delta_{\mathrm{T}}$ were then obtained. Comparing this estimated $\rho_{\mathrm{a}(\mathrm{e})} V_{\mathrm{a}(\mathrm{e})}{ }^{2}$ with the $\rho_{\mathrm{a}(\mathrm{o})} V_{\mathrm{a}(\mathrm{o})}{ }^{2}$ and the $\mathrm{MOE}_{\mathrm{a}(\mathrm{o})}$, obtained from the experiments in the air-drying state, the estimation accuracy was verified. The estimation accuracy are collectively summarized in Table 4. As shown in Table 4, the estimation accuracies for any measurement points of pith and mature wood were also very high; for $\rho_{\mathrm{a}(\mathrm{o})} V_{\mathrm{a}(\mathrm{o})}{ }^{2}$ and $\mathrm{MOE}_{\mathrm{a}(\mathrm{o})}$, the overall estimation accuracies were $1.00 \pm 0.09$ and $1.12 \pm 0.12$, respectively. The estimation accuracy for $\mathrm{MOE}$ was lower than the case of $\rho V^{2}$. As mentioned above, this is because the Young's modulus of the timber calculated from the stress wave propagation velocity and density with $\rho V^{2}$ is different from the MOE obtained by bending test in the first place.

Next, the estimation accuracy of the Young's modulus, corrected to a moisture content of $15 \%$, was examined. 
For the estimated $\rho_{15(\mathrm{e})} V_{15(\mathrm{e})}{ }^{2}$, the stress wave propagation velocity under $15 \%$ moisture content, $V_{15(\mathrm{e})}$, was derived from the stress wave propagation velocity under high-moisture condition, $V_{\mathrm{b}(\mathrm{o})}$ (moisture content before drying, $u_{\mathrm{b}}$ ), using the $u-V_{u} / V_{0}$ relationship, obtained in this analysis; the density under $15 \%$ moisture content, $\rho_{15(\mathrm{e})}$, was derived from the density under high-moisture content condition, $\rho_{\mathrm{b}(\mathrm{o})}$, using a same method as described before, that is, with Eq. (7), then $\rho_{15(\mathrm{e})} V_{15(\mathrm{e})}{ }^{2}$ was calculated. On the other hand, for the observed value of Young's modulus, the moisture content correction was carried out from individual data of moisture content $u_{a}$, using the ASTM D2915-98 method [21] with the following equation.

$E_{15}=E_{\mathrm{a}} \times \frac{(\gamma-\beta \cdot 15)}{\left(\gamma-\beta \cdot u_{\mathrm{a}}\right)}$.

Here, extracted from ASTM [21], $\gamma=1.44, \beta=0.0200$. When the Young's modulus $E_{\mathrm{a}}$ in the Eq. (8) is $\rho_{\mathrm{a}(\mathrm{o})} V_{\mathrm{a}(\mathrm{o})}{ }^{2}$ or $\mathrm{MOE}_{\mathrm{a}(\mathrm{o})}$, the Young's modulus $E_{15}$ in the Eq. (8) will become $\rho V^{2}$ or MOE, respectively (hereafter, referred to as $\rho V^{2}{ }_{15 \text { (ASTM) }}$ or $\mathrm{MOE}_{15(\mathrm{ASTM})}$, respectively). For the results, the estimation accuracy is shown in Table 4. For $\rho V^{2}{ }_{15 \text { (ASTM) }}$ and $\mathrm{MOE}_{15 \text { (ASTM) }}$, the average estimation accuracies in total were $1.02 \pm 0.09$ and $1.13 \pm 0.12$, respectively. That is, also for the estimation of Young's modulus at $15 \%$ moisture, it is shown that the $\rho_{15(\mathrm{e})} V_{15(\mathrm{e})}{ }^{2}$, derived from density, moisture content, stress wave propagation velocity in the high-moisture content stage, exceeding the FSP, is nearly accurate to the $\rho V^{2}{ }_{15 \text { (ASTM) }}$, obtained using the $u-V_{u} / V_{0}$ relationship in this analysis; furthermore, even the MOE can be estimated within an error of $10-20 \%$.

\section{Estimation by Monte Carlo simulation without density}

As described above, using the $u-V_{u} / V_{0}$ relationship analyzed in this study, it was feasible to estimate the Young's modulus in the air-drying state $\left(\rho V^{2}\right.$ or MOE) with high accuracy from the stress wave propagation velocity $V_{\mathrm{b}(\mathrm{o})}$, measured at high moisture content. However, since the measurement of both density and moisture content are required for this estimate, the work onsite is, therefore, complicated, in particular when the measurement target is the $\log$, these measurements are practically impossible. Therefore, the Young's modulus estimation was examined without using these parameters to determine the accuracy of estimation.

First, when the density was unknown, that is, only the stress wave propagation velocity and the moisture content were known, the estimation accuracy of MOE was verified. The moisture content in this case is not the moisture content on surface; it is the average moisture content of the timber as a whole. The estimation was carried out using the Monte Carlo simulation method [22]. That is, using the existing database, related to the density-Young's modulus relationship of the full-scale timber in the air-dying state, on a simulation with random numbers, the Young's modulus was estimated from the stress wave propagation velocity only, without measuring the density. The database of Japanese cedar ( $n=7875)$ was used as the reference [23]. While setting the moisture contents of the estimated Young's modulus for comparison, there were the experimental value during the measurement, $u_{\mathrm{a}}$, and the average equilibrium moisture content of Japan at $15 \%$. The estimation accuracy (estimated value/observed value) is shown in Table 4. In addition, Fig. 7 shows the comparison of the estimated $E_{\mathrm{m}(\mathrm{e})}$ and $\mathrm{MOE}_{(\mathrm{o})}$, in which the measurement points of stress wave propagation velocity on the pith are taken as an example of the relationship between estimated value and observed value. Figure 7a shows the comparison in the case of the moisture content after drying, $u_{a}$; also, Fig. $7 \mathrm{~b}$ shows a comparison in the case of $15 \%$ moisture content. As shown in Table 4, for $\rho_{(\mathrm{o})} V_{(\mathrm{o})}{ }^{2}$ and $\mathrm{MOE}_{(\mathrm{o})}$ for any moisture content, the estimation errors of $E_{\mathrm{m}(\mathrm{e})}$ (that is, $E_{\mathrm{ma}(\mathrm{e})} / \rho_{\mathrm{a}(\mathrm{o})} V_{\mathrm{a}(\mathrm{o})}{ }^{2}, E_{\mathrm{ma}(\mathrm{e})} / \mathrm{MOE}_{\mathrm{a}(\mathrm{o})}, E_{\mathrm{m} 15(\mathrm{e})} / \rho V_{15(\mathrm{ASTM})}{ }^{2}, E_{\mathrm{ma}(\mathrm{e})} /$
Fig. 7 Estimation accuracy of bending Young's modulus without using density data. a Moisture content at experiment and $\mathbf{b}$ moisture content of $15 \%$
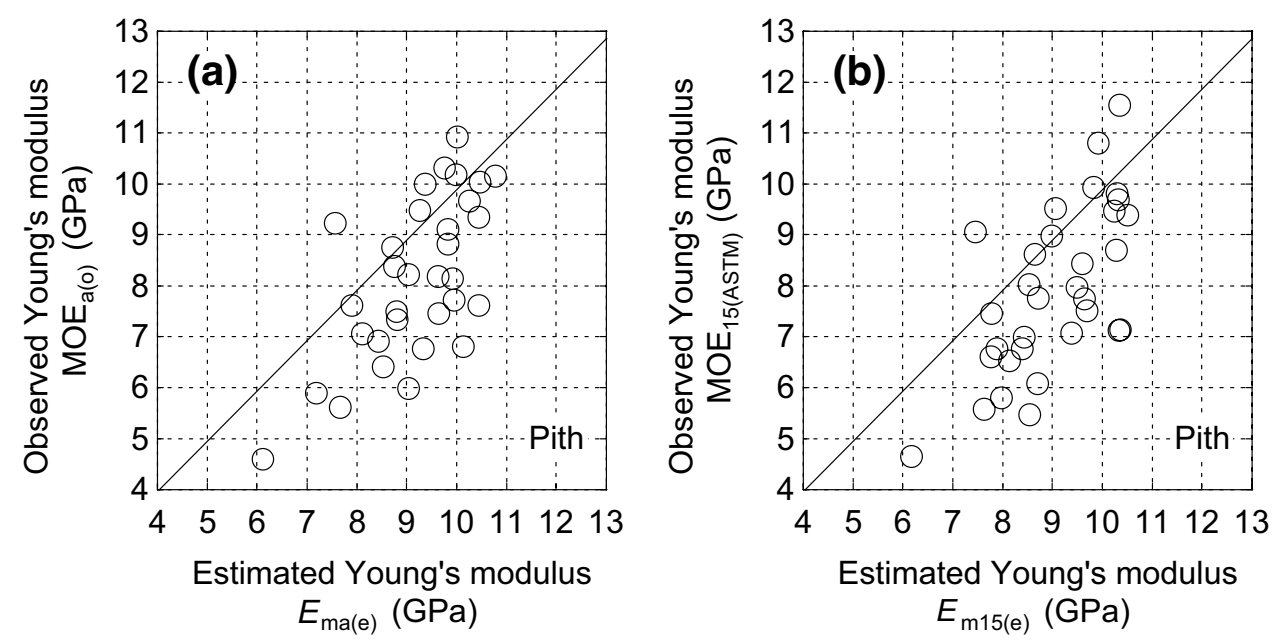
$\mathrm{MOE}_{15 \text { (ASTM) }}$ ) were within $10 \%$ and $20 \%$, respectively. The estimation accuracy only dropped slightly, compared to the results derived from the measured density, as described above. The estimated values were larger than the observed values because the density of the specimen used in this experiment is considered to be slightly lower [ $(379 \pm 37) \mathrm{kg}$ $\mathrm{m}^{-3}$ ], compared to the density distribution of the database used as a reference in the Monte Carlo simulation method $\left[(411 \pm 45) \mathrm{kg} \mathrm{m}^{-3}\right]$. Nonetheless, the extent of this error is very insignificant. Using this estimation method it is possible to ensure practical estimation accuracy without measuring the density.

\section{Estimation accuracy without MC data}

Onsite at a log market, it is often difficult to obtain the real moisture content of full-scale timbers instantly and nondestructively. Therefore, for the case where both density and moisture content are unknown, that is, only the stress wave propagation velocity can be measured, examining whether it is possible to estimate the Young's modulus in the air-drying state with some accuracy was carried out. First, an arbitrary moisture content above the FSP was assumed to be corresponding to the stress wave propagation velocity in high-moisture condition (before drying), $V_{\mathrm{b}(\mathrm{o})} ; V_{15(\mathrm{e})}$ in the air-drying state (moisture content of $15 \%$ ) was estimated from the stress wave propagation velocity $V_{\mathrm{b}(\mathrm{o})}$ at that time using the $u-V_{u} / V_{0}$ relationship obtained in this study. Subsequently, using a Monte Carlo simulation method as described above, the Young's modulus in the air-drying state (moisture content of $15 \%), E_{\mathrm{m} 15(\mathrm{e})}$, was estimated from this $V_{15(\mathrm{e})}$ and compared with the observed value, $\mathrm{MOE}_{15 \text { (ASTM) }}$. As an example, the results in the case of measurement on the pith are shown in Fig. 8, with the horizontal axis as the accuracy of moisture content, that is

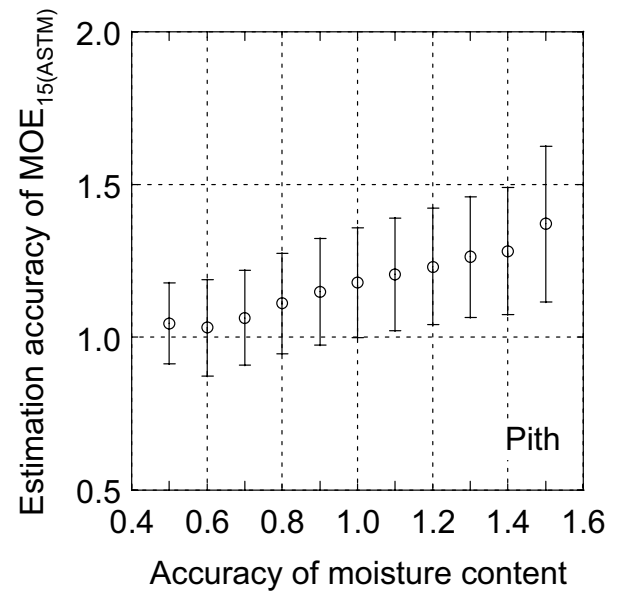

Fig. 8 Change of estimation accuracy of $\mathrm{MOE}_{15}$ caused by estimation error of moisture content the ratio of the assumed value over the real measured value, $u_{\mathrm{b}}$; if the value is closer to 1 , it means that the assumed value is closer to the measured value of the moisture content. The vertical axis is the estimated accuracy of MOE in the air-drying state (moisture content of 15\%). From Fig. 8, when the assumed value of moisture content is half of the true value ( 0.5 on the horizontal axis), the estimation accuracy of $\mathrm{MOE}_{15 \text { (ASTM) }}$ becomes $1.04 \pm 0.13$; in contrast, when the assumed value of moisture content is 1.5 times (1.5 on the horizontal axis), the estimation accuracy of MOE becomes $1.37 \pm 0.26$. For instance, in a full-scale timber of $80 \%$ moisture content, MOE is estimated by assuming the moisture content as $40 \%$. Although the assumed moisture content is incorrect, the estimated value is about the same as the observed value. As mentioned above, this is because the Young's modulus derived via the Monte Carlo method without measuring the density has been overestimated about $20 \%$. This point is offset by having underestimated the moisture content, the resulting estimation accuracy hence improves. Conversely, assuming $120 \%$ moisture content on an $80 \%$ moisture content of a full-scale timber to estimate MOE, the value is being overestimated by about $40 \%$. For this result, the difference in the measurement position is hardly found.

From above, even when both the density and the moisture content were not known, while measuring the stress wave propagation velocity $V_{\mathrm{b}}$, of full-scale timber above the FSP, if the moisture content was set to be lower in the analysis, it was suggested that the Young's modulus of full-scale timber in the air-drying state could be estimated with a relatively good accuracy. Being able to estimate the Young's modulus in the air-drying state at the stage of $\log$ is a very useful technique for efficient utilization of wood; that is, using the appropriate wood in the appropriate place.

\section{Conclusion}

In this study, aiming to estimate the Young's modulus of full-scale timber in the air-drying state from the stress wave propagation velocity measurement under high-moisture condition, the effect of moisture content on the stress wave propagation velocity was investigated. That is, having measured the stress wave propagation velocity, moisture content, density and Young's modulus of the timber before drying and after drying, these experimental data were used via numerical analysis to derive the relationship between moisture content and rate of change of velocity of the full-scale timber. Using the obtained relationships, the Young's modulus of timber in the air-drying state was estimated from the stress wave propagation speed under 
high-moisture condition and its effectiveness was verified. The obtained results are as follows:

1. Using the relationship between moisture content and rate of change of velocity, derived via numerical analysis, the stress wave propagation velocity and the Young's modulus could be estimated from the density, moisture content and stress wave propagation velocity of full-scale timber before drying (moisture condition above the fiber saturation point) with high accuracy. For the estimation of stress wave propagation velocity, the results were verified experimentally and even with different tree species, the relationship equations derived in this study were fully applicable.

2. In the case that the density cannot be measured, using the existing database of mechanical properties with Monte Carlo simulation method, the Young's modulus of full-scale timber in the air-drying state could be estimated from the moisture content and the stress wave propagation velocity before drying within an estimation error of $20 \%$.

3. Even when both density and moisture content are unknown, if the moisture content is set lower in the analysis, the Young's modulus in bending (MOE) of full-scale timber in the air-drying state could be calculated from its stress wave propagation velocity before drying.

\section{References}

1. Sobue N (1995) Grading of tree, log, lumber and wood-based material using Young's modulus (in Japanese). In: The Japan wood research society, Working group of wood-based materials and timber engineering 1995 autumn symposium 'Performance evaluation and non destructive test of wood-based materials', Nagoya international exhibition hall, Nagoya

2. Sandoz JL (1989) Grading of construction timber by ultrasound. Wood Sci Technol 23:95-108

3. Sandoz JL (1993) Moisture content and temperature effect on ultrasound timber grading. Wood Sci Technol 27:373-380

4. Nanami N, Nakamura N, Arima T, Okuma M (1993) Measuring the properties of standing trees with stress wave III. Evaluating the properties of standing trees for some forest stands (in Japanese). Mokuzai Gakkaishi 39:903-909

5. Nakamura N (1996) Measurement of the properties of standing trees with ultrasonics and mapping of the properties' (in Japanese). Bull Tokyo Univ For 96:125-135

6. Ikeda K, Kino N (2000) Quality evaluation of standing trees by a stress-wave propagation method and its application I. Seasonal change of moisture contents of sugi standing trees and evaluation with stress wave propagation velocity (in Japanese). Mokuzai Gakkaishi 46:181-198
7. Ikeda K, Arima T (2000) Quality evaluation of standing trees by a stress-wave propagation method and its application II. Evaluation of sugi stands and application to production of sugi (Cryptomeria japonica D. Don) structural square sawn lumber (in Japanese). Mokuzai Gakkaishi 46:189-196

8. Wang X, Ross RJ, Green DW, Brashaw B, Englund K, Wolcott M (2004) Stress wave sorting of red maple logs for structural quality. Wood Sci Technol 37:533-537

9. Ishiguri F, Matsui R, Iizuka K, Yokota S, Yoshizawa N (2008) Prediction of the mechanical properties of lumber by stress-wave velocity and Pilodyn penetration of 36-year-old Japanese larch tress. Holz Roh Werkst 66:275-280

10. Unterwieser H, Schickhofer G (2011) Influence of moisture content of wood on sound velocity and dynamic MOE of natural frequency- and ultrasonic runtime measurement. Eur J Wood Prod 69:171-181

11. Sobue N (1993) Simulation study on stress wave velocity in wood above fiber saturation point (in Japanese). Mokuzai Gakkaishi 39:271-276

12. Wang SY, Chuang ST (2000) Experimental data correction of the dynamic elastic moduli, velocity and density of solid wood as a function of moisture content above the fiber saturation point. Holzforschung 54:309-314

13. Wang SY, Chiu CM, Lin CJ (2002) Variations in ultrasonic wave velocity and dynamic Young's modulus with moisture content for Taiwania plantation lumber. Wood Fiber Sci 34:370-381

14. Guan H, Nishino Y, Tanaka C (2002) Estimation of moisture content in sugi wood with sound velocity during natural drying process (in Japanese). Mokuzai Gakkaishi 48:225-232

15. Kodama Y (1990) A method of estimating the elastic modulus of wood with variable cross-section forms by sound velocity. I. Application for logs (in Japanese). Mokuzai Gakkaishi 36:997-1003

16. Arriaga F, Íñiguez-González G, Esteban M, Divos F (2012) Vibration method for grading of large cross-section coniferous timber species. Holzforschung 66:381-387

17. Sakai H, Minamisawa A, Takagi K (1990) Effect of moisture content on ultrasonic velocity and attenuation in woods. Ultrasonics 28:382-385

18. Lee CJ, Wang SY, Yang TH (2011) Evaluation of moisture content changes in Taiwan red cypress during drying using ultrasonic and tap-tone testing. Wood Fiber Sci 43:57-63

19. Chan JM, Walker JC, Raymond CA (2011) Effects of moisture content and temperature on acoustic velocity and dynamic MOE of radiate pine sapwood. Wood Sci Technol 45:609-626

20. Fushitani M (1985) Shrinkage and swelling. In: Fushitani M et al (eds) Wood science 2/ physics of wood, Buneido Shuppan, Tokyo, p 62

21. ASTM D2915-98 (1998) Standard practice for evaluating allowable properties for grades of structural lumber. ASTM International, West Conshohocken

22. Yamasaki M, Sasaki Y (2010) Determining Young's modulus of timber on the basis of a strength database and stress wave propagation velocity I: an estimation method for Young's modulus employing Monte Carlo simulation. J Wood Sci 56:269-275

23. Yamasaki M, Sasaki Y, Iijima Y (2010) Determining Young's modulus of timber on the basis of a strength database and stress wave propagation velocity II: effect of the reference distribution database on the determination. J Wood Sci 56:380-386 